\title{
TotShots: An Innovative Pediatric Free Clinic Providing High Patient Satisfaction to the Underserved
}

Jamie LaGrandeur, BA; Maria Moros, MS; Jenna Dobrick, BA; Rombod Rahimian, MPH;

Aida Siyahian, MS; Emily Tomlinson, BS; Paul Gordon, MD, MPH

BACKGROUND AND OBJECTIVES: The University of Arizona College of Medicine-Tucson TotShots clinic is a student-developed, student-directed free clinic that provides sports physicals and vaccines to uninsured pediatric patients in Tucson, Arizona. TotShots runs under the greater umbrella of the Commitment to Underserved People Program, which aims to teach medical students how socioeconomic and cultural factors impact health and access to health care. Our objective was to study cost savings and patient satisfaction of this clinic.

METHODS: Value of care provided through sports physicals and vaccine administration was calculated using the Centers for Medicare and Medicaid Services Physician Fee Schedule and Centers for Disease Control Vaccines for Children Decisions Analysis Model. In addition, patient satisfaction was measured through the utilization of an optional three-question survey completed by patients in their preferred language at the resolution of their visit. Vaccines and sports physicals were administered from April 2017 to November 2017.

RESULTS: TotShots administered 51 vaccines and completed 115 sports physicals resulting in a value of $\$ 415.65$ of administration fees and $\$ 5,878.80$ of sports physical examinations. Sixty-three of 66 total patients completed patient satisfaction surveys. Of those patients, $57(90.5 \%)$ were highly satisfied with their provider's communication, 58 (92\%) rated their perception of the quality of medical care they received as excellent, and 54 $(\mathbf{8 5 . 7 \% )}$ of patients were highly satisfied with their overall TotShots experience.

CONCLUSIONS: TotShots fills a valuable role in increasing access to vaccines and sports physicals while maintaining high patient satisfaction and high value of cost savings.

(Fam Med. 2018;50(10):779-81.)

doi: 10.22454/FamMed.2018.678901

$\mathbf{U}$ niversity of Arizona College of Medicine-Tucson's (UACOM-T) TotShots clinic is a student-developed and directed clinic that provides sports physicals and vaccines to uninsured children ages 0 to 18 years in Tucson, Arizona. TotShots provides free continuity of care to patients by referring student-directed program that operates under an integrated electronic medical record (EMR) system that provides students the opportunity to enhance their clinical skills by working directly with medically underserved populations. The patients who attend TotShots come from a unique community consisting of refugees and a Mexican-American border population. We strive to ensure that uninsured or undocumented children in the Tucson area who would like to participate in sports may do so in a healthy and safe manner.

TotShots is able to address an unmet need in the community by providing sports physicals and vaccinations to children who would otherwise be ineligible to participate in sports. In this study, we examined the value of services and patient satisfaction related to the care provided to this population by medical students at TotShots. While there have been other studies measuring patient satisfaction and value savings of student-run free clinics, none have combined the two metrics to be analyzed together in one clinic. ${ }^{2-6} \mathrm{By}$ measuring the value of services and patient satisfaction, we were able to determine the quality of care that a student-run clinic can provide to its immediate community and the value it has on the patients using

From the University of Arizona College of Medicine. 
our services. Congruently, medical students gain exposure to cost savings and its relationship to patient satisfaction, providing them with insight into some challenges faced by patients.

\section{Methods}

We examined the cost of physical examinations and vaccine administration as well as patient satisfaction at TotShots. The clinic is funded by private donations, and vaccines are provided by the Centers for Disease Control (CDC) Vaccines for Children program. All vaccines and sports physicals are administered by volunteer medical students under the supervision of an attending physician. Patients are recruited using social media, and email communication with school district social workers, coaches, and nurses. The patients are ineligible for insurance programs due to their immigration or financial status; insurance status is assessed via a questionnaire at intake. A convenience sample of respondents to our social media and email outreach campaign was the patient group in this study. Parents of patients were surveyed using an instrument created by CUP students through small group discussion in 2017 for use in the TotShots program. No statistical program was used for the simple analysis of questionnaire responses. This three-question, optional survey measured patient satisfaction and was completed by patients' parents at the resolution of their visit in their preferred language, including English and Spanish.

TotShots administered 51 vaccines and performed 115 sports physicals from April 2017 to November 2017. The Centers for Medicare and Medicaid Services Physician Fee Schedule provided the metrics used for calculating fees of sports physicals. ${ }^{7}$ Vaccine administration fees were calculated using the CDC Vaccines for Children Decisions Analysis Model. ${ }^{8}$ This model provides cost savings for vaccine administration nationwide and estimates that cost savings of one vaccine in a public clinic is $\$ 8.15$. The Physician Fee Schedule estimates that one sports physical costs $\$ 51.12$ for an outpatient clinic setting in the state of Arizona. The University of Arizona Institutional Review Board granted this study an exemption from formal review.

\section{Results}

According to metrics for a public clinic, TotShots has provided $\$ 415.65$ in value usually billed for administration of 51 vaccines, and provided $\$ 5,878.80$ in free sports physical examinations based on 115 sports physicals performed. Table 1 shows demographic information for patients receiving both sports physical and vaccine services, while Table 2 shows a breakdown of each vaccine given. From April 2017 through November 2017, 63 of 66, total patients' parents have completed quality control surveys resulting in a $95 \%$ response rate. Of those patients, 57 (90.5\%) were highly satisfied with their health care provider's communication, while three $(4.7 \%)$ were satisfied, and three $(4.7 \%)$ were neutral. Fifty-eight (92\%) patients rated their perception of the quality of medical care they received as excellent, two (3.1\%) as good, and three

Table 1: Patient Demographics (April 1, 2017-November 30, 2017)

\begin{tabular}{|l|c|c|c|c|c|}
\hline & $\begin{array}{c}\text { Total Number } \\
\text { of Patients }\end{array}$ & $\begin{array}{c}\text { Total Number of } \\
\text { Females (\%) }\end{array}$ & $\begin{array}{c}\text { Total Number } \\
\text { of Males (\%) }\end{array}$ & Mean Age & Standard Deviation \\
\hline Vaccines & 19 & $12(63.2 \%)$ & $7(36.8 \%)$ & 9.3 & 4.5 \\
\hline Sports physicals & 115 & $57(49.6 \%)$ & $58(50.4 \%)$ & 14.62 & 2.37 \\
\hline
\end{tabular}

Table 2: Vaccine Breakdown (April 1, 2017-November 30, 2017)

\begin{tabular}{|l|c|c|}
\hline & Number of Vaccines & Percent of Total Vaccinations \\
\hline Varicella & 5 & 9.8 \\
\hline IPV & 4 & 7.8 \\
\hline DTaP & 4 & 7.8 \\
\hline Meningococcal MVC4P & 9 & 17.6 \\
\hline Tdap & 10 & 19.6 \\
\hline Hib (PRP-OMP) & 2 & 3.9 \\
\hline HPV 9 & 6 & 11.8 \\
\hline Pneumococcal conjugate PCV 13 & 1 & 1.9 \\
\hline Hep A & 4 & 7.8 \\
\hline Influenza injectable quadravalent & 1 & 1.9 \\
\hline MMR & 5 & 9.8 \\
\hline Total & $\mathbf{5 1}$ & $\mathbf{1 0 0}$ \\
\hline
\end{tabular}


(4.7\%) as neutral. Fifty-four (85.7\%) patients were highly satisfied with their overall TotShots experience, eight $(12.7 \%)$ were satisfied, and one (1.6\%) was neutral.

\section{Discussion}

TotShots provides uninsured children in Tucson with sports physicals and vaccines without financial burden at high patient satisfaction, while allowing medical students to enhance their training through clinical community service. Through the program, medical students provided $\$ 6,294.45$ of value in services for patients served from April 2017 through November 2017.

According to the CDC, the majority of our population has vaccination rates of less than $50 \%$ at 36 months. ${ }^{9}$ Through the CDC Vaccines for Children program, TotShots provides vaccines at no cost to the patient with the added benefit of no clinic administration costs. Patients receive physical exams they may not otherwise receive due to lack of access and burden of cost. We believe patient satisfaction is related to medical student communication, available translation services, timely appointments, decreased waiting times, EMR integration, and consistent clinic availability. TotShots plays a valuable role in increasing access to preventive services for uninsured children in Tucson who may not otherwise receive them, with the goal of keeping them healthy and engaged in their school activities.

This study is unique because it combines patient satisfaction with value savings in a student-run free clinic. Limitations include short time frame of study, small scope of services offered, and inherent response bias found in patient satisfaction surveys. Subsequent work may include further analysis of patient satisfaction and comparison with other student-run free clinics that serve children, a demographic less often seen than adults in free clinics. ${ }^{10}$

ACKNOWLEDGMENTS: This study was presented at the American Association of Medical Colleges' Learn, Serve, Lead Conference, November 3, 2017, Boston, MA.

CORRESPONDING AUTHOR: Address correspondence to Jamie LaGrandeur, University of Arizona College of Medicine, 1501 N Campbell Ave, Tucson, AZ 85724. 541-912-5902. jamielag@email.arizona.edu.

\section{References}

1. University of Arizona Health Sciences. Commitment to underserved people (CUP) programs. http://medicine.arizona.edu/education/ other/commitment-underserved-people. Updated 2017. Accessed December 15, 2017.

2. Ellett JD, Campbell JA, Gonsalves WC. Patient satisfaction in a student-run free medical clinic. Fam Med. 2010;42(1):16-18.

3. Clark JS, Bollaert A, Sills SO, Clark JH, Norris D. Patient perception of care received by students at the Jackson Free Clinic. J Miss State Med Assoc. 2014;55(4):113-118.
4. Fröberg M, Leanderson C, Fläckman B, et al. Experiences of a student-run clinic in primary care: a mixed-method study with students, patients and supervisors. Scand J Prim Health Care. 2018;36(1):36-46.

5. Lawrence D, Bryant TK, Nobel TB, Dolansky MA, Singh MK. A comparative evaluation of patient satisfaction outcomes in an interprofessional student-run free clinic. J Interprof Care. 2015;29(5):445-450.

6. Stuhlmiller CM, Tolchard B. Developing a student-led health and wellbeing clinic in an underserved community: collaborative learning, health outcomes and cost savings. BMC Nurs. 2015;14(1):32.

7. Centers for Medicare and Medicaid Services. License for Use of Current Procedural Terminology, Fourth Edition. https://www.cms. gov/apps/physician-fee-schedule/search/searchresults. aspx? $\mathrm{Y}=0 \& \mathrm{~T}=4 \& \mathrm{HT}=0 \& \mathrm{CT}=2 \& \mathrm{H} 1=$ $99213 \& \mathrm{C}=42 \& \mathrm{M}=5$. Updated 2017. Accessed December 15, 2017.

8. Centers for Disease Control and Prevention. Vaccines for Children Publications: Supplement. https://www.cdc.gov/vaccines/programs/ vfc/pubs/methods/index.html. Updated 2014. Accessed December 15, 2017.

9. Leeds M, Muscoplat MH. Timeliness of receipt of early childhood vaccinations among children of immigrants -Minnesota, 2016. MMWR Morb Mortal Wkly Rep. 2017;66(42):1125-1129.

10. Simpson S, Long J. Medical student-run health clinics: Important contributors to patient care and medical education. J Gen Intern Med. 2007;22(3):352-356. 